\title{
FEIÇÕES MORFOLÓGICAS ENTRE A BAÍA DO RUSSO E A FOZ DO RIO CABAÇAL, SUDOESTE DE MATO GROSSO
}

\author{
Sebastião dos Santos Junior ${ }^{(a)}$ Célia Alves de Souza ${ }^{(b)}$ Vanilda Soares Prudêncio ${ }^{(c)}$ Thales \\ Enildo de Lima ${ }^{(d)}$ \\ ${ }^{(a)}$ Departamento Geografia Universidade do Estado de Mato Grosso (UNEMAT) e- \\ mail:sebastiaocloser@gmail.com \\ ${ }^{(b)}$ Departamento Geografia UNEMAT e-mail: celiaalvesgeo@globo.com \\ ${ }^{(c)}$ Departamento Geografia UNEMAT e-mail:vanildaster96@gmail.com \\ (d)Departamento Geografia UNEMAT e-mail:lima.thales@outlook.com
}

\section{EIXO: BACIAS HIDROGRÁFICAS E RECURSOS HÍDRICOS: ANÁLISE, PLANEJAMENTO E GESTÃO}

\begin{abstract}
Resumo
O presente estudo objetivou analisar em escala temporal a ocorrência de feições morfológicas entre a baía do Russo e a foz do rio Cabaçal no período de trinta anos.Realizou-seestudos bibliográficos sobre a temáticae sobre a área de estudo, para confecção da base cartográfica utilizou imagem de satélite e as ferramentas do softwareArcGis 9.3. No trecho estudado verificouse a presença de feições morfológicas, representadas por lagoas, baías e canais secundários. No ano de 1986 foram registrados a ocorrência de seis baías, vinte e duas lagoas e um canal secundário. Em 2016 mantiveram-se as seis baías, oito lagoas desapareceram,houve alteração na dimensão das lagoas e baías, surgiu uma nova baía e quinze novas lagoas.
\end{abstract}

Palavras Chaves:Rio Cabaçal. Feições morfológicas. Dinâmica fluvial

\section{INTRODUÇÃO}

De acordo com Riccomini et. al. (2003), os rios são cursos de água doce, com canaisdefinidos e fluxo permanente ou sazonal que escoa para um oceano, lago ou outro rio. Dada asua capacidade de erosão, transporte e deposição, os rios são os principais agentes detransformação da paisagem.

Os processos de sedimentação, que acontecem no canal ou na planície de inundação,provenientes da atividade do canal, compreendem os depósitos residuais do canal, barras demeandros, barra de canais e do preenchimento de canais (SUGUIO; BIGARELLA, 1990).

Para Souza (2004), as baías constituem áreas deprimidas, contendo água, delineando formas circulares, semicirculares ou irregulares, as baías apresentam-se ligadas diretamente ao canal principal do rio Cabaçal, inclusive em época de estiagem. As lagoas são porções de água circundada de solo, não possuindo ligação direta com o rio podendo ser perenes ou não (abastecidas pelo lençol freático), porém, no período de cheia são abastecidas por água e sedimentos que transbordam do leito do rio. Esse transbordamento pode contribuir para justificar o aumento na dimensão das lagoas no período de cheias e a diminuição da dimensão e desaparecimento de lagoas no período de estiagem por processo de sedimentação (colmatação). 


\section{OS DESAFIOS DA GEOGRAFIA FÍSICA NA FRONTEIRA DO CONHECIMENTO \\ Instituto de Geociências - Unicamp \\ Campinas - SP \\ 28 de Junho à 02 de Julho de 2017}

A bacia hidrográfica do rio Cabaçal, possui suas nascentes na Chapada dos Parecis, com área de 6.042 $\mathrm{km}^{2}$. Percorre um trecho de depressão no alto e médio curso; no baixo curso, divaga pela planície, próxima da confluência com rio Paraguai, sua extensão é de aproximadamente 303,43 km(AVELINO, 2006).

Nas últimas décadas, a bacia hidrográfica do rio Cabaçal vem passando por alterações no meio físico. Devido ao processo de ocupação, os recursos naturais, antes preservados, sofrem processo de degradação. Essasalterações provocam mudanças diretasno leito do rio e na planície de inundação, consequentemente aumentando o aporte de sedimentos no baixo curso (SOUZA, et al., 2013).

O estudo objetivou analisar em escala temporal a ocorrência de feiçõesmorfológicas entre a baía do Russo até a foz do rio Cabaçalna região sudoeste de Mato Grosso, no período de 1986 e 2016.

\section{MATERIAIS E MÉTODO}

\section{1.Área de estudo}

A área de estudo está localizada no rio Cabaçal entre a baía do Russo e a foz do rio Cabaçal,entre as coordenadas geográficas $15^{\circ} 55^{\prime} 50^{\prime}$ ' e $16^{\circ} 00^{\prime} 00^{\prime \prime}$ Latitude Sul e $57^{\circ} 42^{\prime} 30^{\prime \prime}$ e $57^{\circ} 44^{\prime} 10^{\prime \prime}$ Longitude Oeste (figura 1).

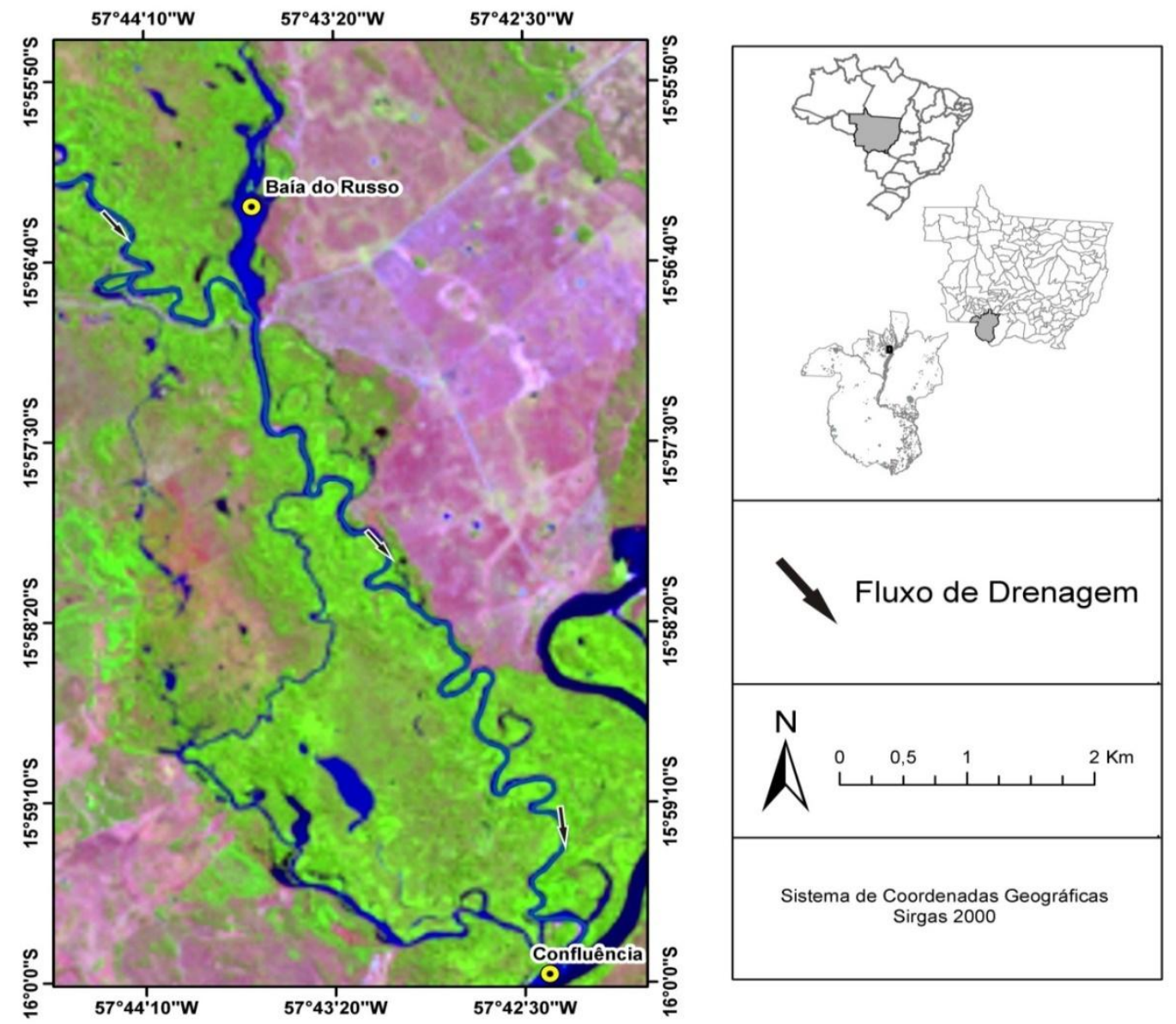

Figura 1 - Localização da área de estudo 


\subsection{Procedimento metodológico}

Foi utilizado imagens dos anos de 1986 e 2016 do satélite LANDSAT 5 e 8 OLI com 30 metros de resolução espacial; posteriormente a imagem passou pela composição de bandas5, 4 e 3 (LANDSAT 5) e para o LANDSAT 8 as bandas 4, 5 e 6 RGB em falsa cor, logo após redimecionadoraster para 15 metros de resolução pela função Pan Sharpen através da banda 8 (Pan) do Landsat 8, inserido arquivo vetorial sobre o mesmo delimitando a área de estudo, recortando oraster através da função ExtractbyMask. Confeccionado layout do mapa.

Para obter omapa das feições morfológicas, criou-se arquivo vetorial, constituindo classes de análise e classificado por sobre cada feição sobre a área de estudo, posteriormente a vetorização, calculado a área dos polígonos em quilômetros quadrados. O mesmo processo segue-se de forma semelhando a todas as imagens. Confeccionado layout do mapa, seguindo normativas cartográficas.

Foram confeccionados osmapas com utilização de Sistema de Informações Geográfico (GIS / SIG) por softwareArcGis9.3 licenciado, sendo interpretado e projetado os mapas.

\section{RESULTADO E DISCUSSÃO}

O uso do SIG (Sistema de Informação Geográfica) mostrou-se eficiente para descrever e analisar as mudanças ocorridas no baixo curso do rio Cabaçal. Pelos resultados da análise espaço-temporal das imagens de satélites dos anos de 1986 e 2016, verificou-se que as alterações na morfologia relacionam-se à erosão fluvial e à deposição de sedimentos.

No baixo curso do rio Cabaçal próximo da confluência com o rio Paraguai,o rio bifurca-se em dois canais formando uma ilha,o ambiente fluvial apresenta distintas características, observa-se a presença de várias feições morfológicas na planície de inundação. O canal secundário está em processo de comaltação, sendo parcialmente obstruído devido o acúmulo de sedimentos na calha.

No ano de 1986 registrou a ocorrência de seis baías, sendo a maior com área de 0,360 km², e a menor com área $0,02694 \mathrm{~km}^{2}$.Aferiu-se também vinte e duas lagoas, a maior com área $0,112707 \mathrm{~km}^{2}$, a menor com área de 0,00301, e um canal secundário com área de $0,729591 \mathrm{~km}^{2}$.

No ano de 2016mantiveram as seis baías, oito lagoas desapareceram, houve alteraçãona dimensão das lagoas e baías, surgiu uma nova baía e quinze novas lagoas e registrou o desaparecimento de oito lagoas (Figura 2). 


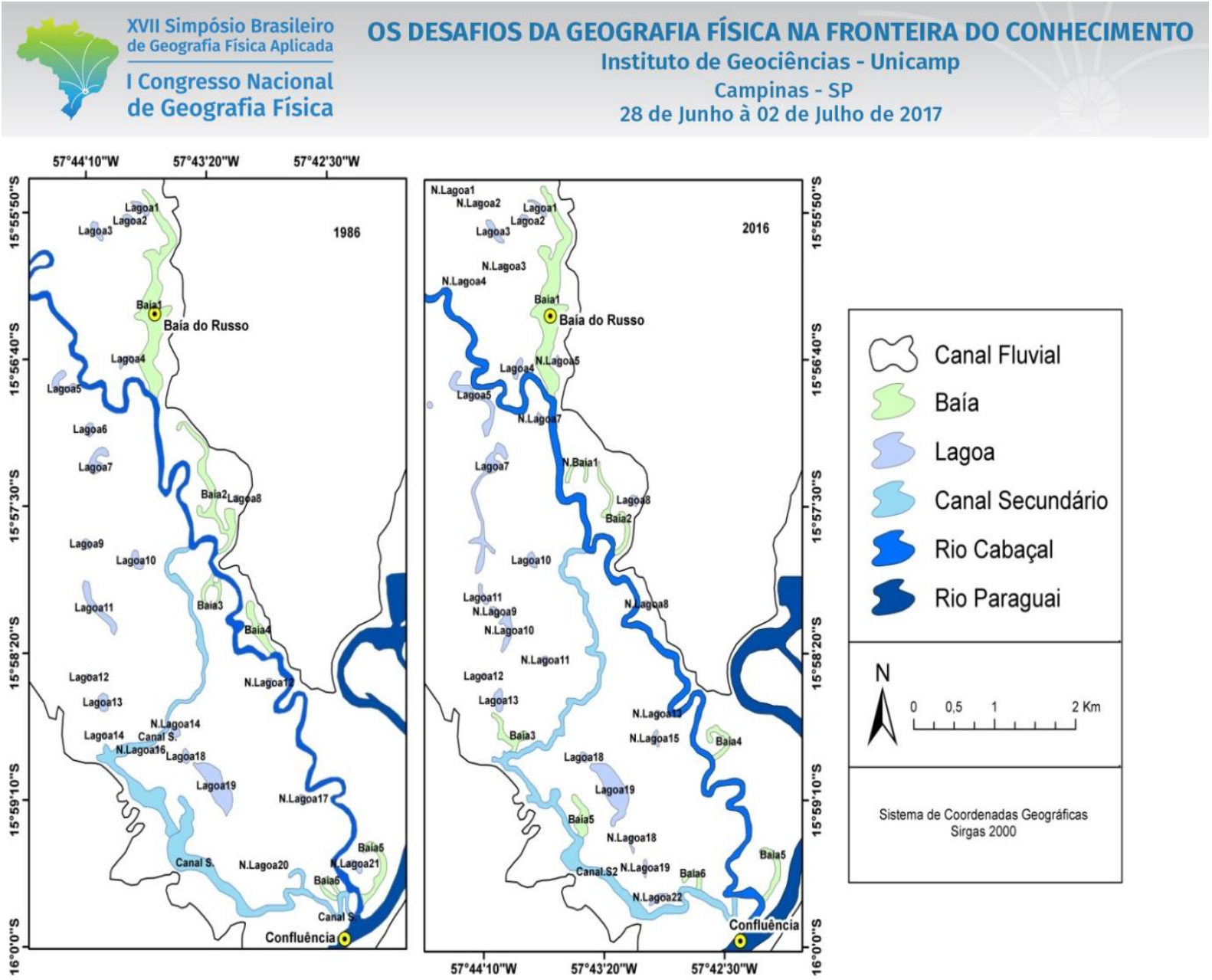

Figura 2:Distribuição espacial das feições morfológicas no rio Cabaçal entre a baía do Russo à confluência como rio Paraguai.

\section{CONSIDERAÇÕES FINAIS}

O estudo permitiu a identificação de feições morfológicas representadas por lagoas, baías e canais secundários. Verificou-se ao longo dos trinta anos alterações nessas feições morfológicas, algumas lagoas e baíassurgiram e outras desapareceram, mudaram também as suas dimensões.

\section{REFERÊNCIAS BIBLIOGRÁFICAS}

AVELINO, P. H. M. Análise Geo-ambiental Multitemporal para fins de Planejamento Ambiental: um exemplo aplicado à Bacia Hidrográfica do Rio Cabaçal, Mato Grosso - Brasil. Tese (Doutorado em Geografia). Rio de Janeiro: Universidade Federal do Rio de Janeiro, 2006, 323 f.

CHRISTOFOLETTI, A. Geomorfologia. $2^{\circ}$ Ed. São Paulo: Blucher, 1980.

RICCOMINI, C.; GIANNINI, P. C.; MANCINI, F. Rios e processos aluviais. In: TEIXEIRA, W.; TOLEDO, M. C. M.; FAIRCHILD, T. R.; TAIOLI, F. (Orgs.). Decifrando a Terra. São Paulo: Oficinas de textos, 2003. p. $191-210$ 
SOUZA, C. A..Dinâmica do corredor fluvial do rio Paraguai entre a cidade de Cáceres e a estação ecológica da Ilha de Taiamã-MT. Tese(Doutorado em Geografia). Rio de Janeiro: Universidade Federal do Rio de Janeiro, 2004

SUGUIO, K.; BIGARELLA, J. J. Ambientes fluviais. 2. ed. Florianópolis: Ed.UFSC/ UFPR, 1990. 183 p.

SOUZA, C. A. et. al. 2013.Sedimentação no rio Paraguai e no baixo curso dos tributários Sepotuba, Cabaçal e Jauru, Mato Grosso Brasil. Anaisdo XIV Encontro de Geógrafos de América Latina,Lima/Peru, 2013. 